\title{
The American Citizen who plays Tennis: Analysis of the Highest-Paid Female Athletes over ten years period.
}

\author{
Temitope Farinloye \\ Questbury Research Services, Kent, UK \\ Temitope.farinloye@questbury.com \\ Emmanuel Mogaji \\ University of Greenwich, London, UK \\ e.o.mogaji@greenwich.ac.uk
}

Forbes Magazine compiles Highest-Paid Female Athletes in the world; the list contains ten female athletes with the highest earning which includes all prize money, salaries and bonuses earned. This present study analysed the content of these ranking over ten years period from 2009 to 2018 to understand the calibre of sportswomen who have achieved that much, the sports they play and perhaps an insight into their personality.

Twenty-five female athletes appeared on the list, from 18 countries, playing six different sports. The study concludes that for a sportswoman to become one of the highest paid female athletes in the world, she must be an American citizen who plays Tennis, as American citizens and Tennis players dominated the list. This highlight implications for governing bodies, talent managers and even sportswomen, especially those in team sports as the list was dominated with athletes in non-team sports. The country of origin seems to be a contributing factor as well. This study adds to the existing literature on sports marketing and celebrity endorsements. Specifically shed more light on sportswomen as individuals, their sports and country of origin. Implications for researchers, policymakers and Managers are provided. Research agenda for future studies were also presented. 


\section{Introduction}

Sportswomen face challenges in becoming brand ambassadors. There are challenges around the sexualisation of sportswomen, the vicious cycle of male popularity and moral compasses (Mogaji, et al., 2018). No doubt some sportswomen have broken through the glass ceiling on the endorsement to be counted among the highest paid athletes in the world. However, this is not always guaranteed as seen in the 2018 Forbes list of highest paid athletes. It was another setback where there were no single women on the top 100 highest paid athletes in the world.

Each year Forbes ranks the world based on a variety of categories, among with is top earners in Sports. Forbes presents the list of top 100 highest paid athletes based on earnings figures which include all prize money, salaries and bonuses earned. It is acknowledged that Forbes' lists of topearning athletes have long been testosterone-heavy (Badenhausen, 2018), however the possibilities of having more women on that list is worth considering - an indication of how much brands considers the worth of sportswomen, how well they engage with the public and how the public has perceived their brands as a credible endorser.

Perhaps to address this dominance of men in sports endorsement, Forbes has a list of highestpaid female athletes. This list is however limited to just ten female athletes. While not considering this list as sense equality and closure of the pay gap in sports, the most overt manifestation of gender inequality, this research focuses explicitly on the Forbes list of highest paid female athletes. The study analysed the top 10 female athletes for the past ten years. This study is aimed at the understanding calibre of sportswomen who have achieved that much, the sports they play and perhaps an insight into their personality. It is expected that the research will add to the existing literature on sports marketing and celebrity endorsements. Specifically shed more light on these individuals, their sports and country of origin. Implications for researchers, policymakers and Managers are provided.

The subsequent section introduces the methodology for the study, and the results are presented in section 3. Theoretical and managerial implications, including research agendas for future studies, were discussed in the following. Section 5 presents the conclusion. 


\section{Methodology}

Content Analysis

Content analysis is considered a technique for an objective, systematic and quantitative description of the manifest content of communication (Berelson, 1952), It is a research technique for making replicable and valid inferences from the data to their context (Krippendorff, 2013). Content analysis is a valid research method because it provides data that are empirical, systematic and objective (Chan \& Cheng, 2012). This method has been used in analysing the content of YouTube videos, print advertisements (Mogaji, et al., 2018) and even user-generated comments on social media (Mogaji, 2016; Mogaji, et al., 2016). The method is considered suitable for structured data such as a fixed list like the Forbes ranking. The athletes can be coded based on their sport and country to gain empirical insight into the frequency and prevalence of athlete, sports or country on the list over the ten years.

\section{Data collection}

The primary data for the study was the name of the ten highest paid females over ten years, between 2009 and 2018. This data was primarily based on information from Forbes and was also complemented with Topend Sports (Topend Sports, 2029). 2009 list however only had five names of female athletes, and that makes a list of 95 athletes throughout the ten years. Though there were athletes that appeared multiple times over the period, their name was included in the whole sample. Their sport, country of origin and money prize were collected. The table containing each year's ranking was printed out for data analysis and codebook development.

\section{Coding Procedure}

To guarantee the objectivity and reliability of the results, two individuals, independent of each other, served as the coders. A Google form was created to allow the coders independently code the athletes from the list that has been printed out. The coders coded 50 athletes each. The year of the ranking (2009-2018), the position on the table $\left(1^{\text {st }}-10^{\text {th }}\right)$, Name of athletes, Sports, Country of Origin and earning were coded by the coders. The data was downloaded as an Excel spreadsheet from the Google form. The spreadsheet was only accessible to the researchers. The spreadsheet was after that exported into SPSS for the descriptive analysis. The coders were not involved in the research and were not familiar with the design of the study or its purposes. As adopted by (Mogaji, 2015), several dimensions were used and, following the research questions described above, the different categories of the analysis were pre-tested. Taking into consideration the size of the data, the coders were offered an hour of training, which began with 
an explanation of the content analysis method and the processes involved. They were offered the codebooks, and meetings were held to make sure they were being used consistently. This is the guideline recommended by Kolbe and Burnett (Kolbe \& Burnett, 1991)

\section{Intercoder reliability}

To test the intercoder reliability and to make sure the coders understand the coding process, thirty male athletes (top ten from three years on the Forbes list) were selected to test the intercoder reliability between the two coders. The different categories of the analysis were pretested, and each coder coded the advertisement, and their findings were compared. An intercoder reliability check was assessed using both Cohen's Kappa and Krippendorff's alpha. The level of agreement was 1.00. As Neuendorf (2002) concludes that "coefficients of 0.90 or higher would be acceptable to all, the intercoder reliability offers an indication that they both understand the concept and able to use the provided data to fill the Google Form accurately.

\section{Results}

\section{The Athletes}

As presented in Table 1, the content analysis of the ranking table revealed that 25 female athletes appeared on the list over the ten years. While some appeared once over the ten years, Serena Williams and Danica Patrick were the most consistent athletes as they appeared on the list throughout the ten years. Serena Willian has been on the list since 2009 when she was $2^{\text {nd }}$ on the list, but she moved into the $1^{\text {st }}$ position in 2016, and she has maintained that position for three consecutive years. Maria Sharapova had an impressive endorsement portfolio which justifies her first position for seven consecutive years from 2009 until 2016 when she dropped to Number 2 and 2017 when she dropped out of top 10. Sharapova was not playing tennis during the Forbes tracking period as she was serving her 15-month suspension for the use of the banned substance. Brands like American Express, Avon and Tag Heuer did not renew their sponsorship deals with her which might have affected her endorsement earnings. She, however, came back in 2018 to position 5. Ana Ivanovic has been on the table since 2009, but she dropped out and was not on the list in 2017 and 2018. Caroline Wozniacki joined the list in 2011 arriving at the second position when she was the world's No. 1 ranked tennis player. These five athletes appeared eight times or more on the list; figure 1 illustrates their movement of the ranking table over the years. 


\begin{tabular}{|c|c|c|}
\hline Athlete & $\begin{array}{c}\text { Frequency } \\
\text { (Number of Times in } 10 \text { years) }\end{array}$ & Per cent \\
\hline Agnieszka Radwanska & 6 & 6.3 \\
\hline Ana Ivanovic & 8 & 8.4 \\
\hline Angelique Kerber & 2 & 2.1 \\
\hline Annika Sörenstam & 1 & 1.1 \\
\hline Caroline Wozniacki & 8 & 8.4 \\
\hline Danica Patrick & 10 & 10.5 \\
\hline Eugenie Bouchard & 2 & 2.1 \\
\hline Garbine Muguruza & 3 & 3.2 \\
\hline Jelena Jankovic & 1 & 1.1 \\
\hline Kim Clijsters & 1 & 1.1 \\
\hline Kim Yuna & 5 & 5.3 \\
\hline $\mathrm{Li} \mathrm{Na}$ & 4 & 4.2 \\
\hline Lorena Ochoa & 1 & 1.1 \\
\hline Maria Sharapova & 9 & 9.5 \\
\hline P.V. Sindhu & 1 & 1.1 \\
\hline Paula Creamer & 4 & 4.2 \\
\hline Petra Kvitova & 1 & 1.1 \\
\hline Ronda Rousey & 3 & 3.2 \\
\hline Serena Williams & 10 & 10.5 \\
\hline Simona Halep & 3 & 3.2 \\
\hline Sloane Stephens & 1 & 1.1 \\
\hline Stacy Lewis & 1 & 1.1 \\
\hline Venus Williams & 5 & 5.3 \\
\hline Victoria Azarenka & 4 & 4.2 \\
\hline Yani Tseng & 1 & 1.1 \\
\hline Total & 95 & 100.0 \\
\hline
\end{tabular}

Table 1: Athletes Appearance on the highest-paid female ranking list over ten years period. 


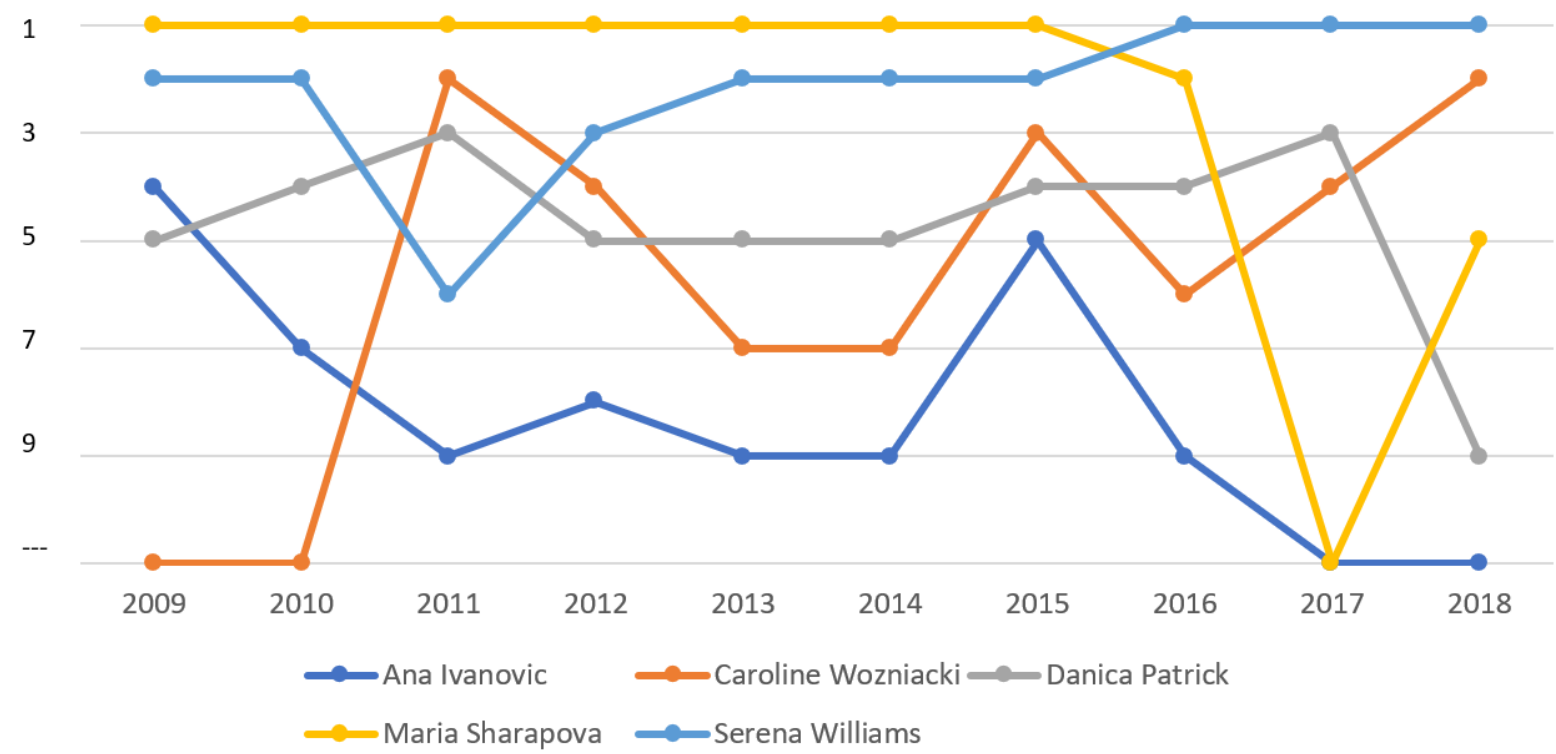

Figure 1: Top 5 consistent athletes over the Ten years

\section{The Sports}

The result identified six sports on the list over the ten years. Table 2 presents the list of sports appearances on the highest-paid female ranking list over the ten years. Auto racing (Danica Patrick), Figure Skating (Kim Yuna), Badminton (P.V. Sindhu) and Mixed Martial Arts (Ronda Rousey) had just only one athlete represented. Golf, however, had five athletes while 15 Tennis athletes dominated the list. The table illustrated the distribution of athletes across different sports.

\begin{tabular}{lc|c|}
\hline Sport & Frequency & Per cent \\
\hline Auto Racing & 2 & 8 \\
\hline Badminton & 1 & 4 \\
\hline Figure Skating & 1 & 4 \\
\hline Golf & 5 & 20 \\
\hline MMA & 1 & 4 \\
\hline Tennis & 15 & 60 \\
\hline Total & 25 & 100.0 \\
\hline
\end{tabular}

Table 2: Sports Appearance on the highest-paid female ranking list over ten years period.

It is worth noting as well that these sports are predominantly non-team sports, athletes can take individual responsibility for their success. P.V. Sindhu is an Indian badminton player who joined 
Forbes's list in 2018 as the highest earning non-tennis female athlete. India has a population of over one billion, and Badminton is one of the most-played sports after cricket in India, it attracts many followers and brands are willing to associate with her after her performance at the Rio 2016 Olympics and 2017,2018 world championship. Her prize money was $\$ 500,000$ while her endorsements was $\$ 8$ million. The big prize money in tennis could have contributed to the high number of athletes on the list over these years. The prize money distributed to Grand Slam victors has been the same for men and women across all four of the major tournaments since 2007. More so, there are many opportunities for tennis players to increase their earning. The 2019 WTA competitive season includes 55 events and four Grand Slams in 29 countries, culminating with the WTA Finals in Shenzhen, China, offering an unprecedented \$14 million total prize purse and honouring the season's top singles and doubles players (WTA, 2019).

\section{The Country}

Athletes from 18 different countries have been on the highest-paid female athlete's list over ten years. Table 3 presents the distributions of the countries on the ranking list over ten years period.16 of the 18 countries have just only one representative, Serbia had two representative Ana Ivanovic and Jelena Jankovic, both playing Tennis while the USA had the highest number of representatives on the list with seven athletes from 4 different sports. Serena Willian and Danica Patrick were the most featured athletes from America on the list; they both appeared throughout the ten years. While Europe, Asia and North America were represented, there were no athletes from Africa and South America on the list.

\begin{tabular}{|r|c|c|}
\hline Country & Frequency & Per cent \\
\hline Belarus & 1 & 4 \\
\hline Belgium & 1 & 4 \\
\hline Canada & 1 & 4 \\
\hline China & 1 & 4 \\
\hline Czech Republic & 1 & 4 \\
\hline Denmark & 1 & 4 \\
\hline Germany & 1 & 4 \\
\hline India & 1 & 4 \\
\hline Mexico & 1 & 4 \\
\hline Poland & 1 & 4 \\
\hline
\end{tabular}




\begin{tabular}{|r|c|c|}
\hline Romania & 1 & 4 \\
\hline Russia & 1 & 4 \\
\hline Serbia & 2 & 8 \\
\hline South Korea & 1 & 4 \\
\hline Spain & 1 & 4 \\
\hline Sweden & 1 & 4 \\
\hline Taiwan & 1 & 4 \\
\hline USA & 7 & 28 \\
\hline Total & 25 & 100.0 \\
\hline
\end{tabular}

Table 3: Country appearance on the highest-paid female ranking list over ten years period.

\section{Discussion}

The study analysed the top 10 highest paid female athletes in the world over ten years. The analysis revealed the number of female athletes that have appeared on the list, their sports and countries. With American Tennis players topping the list of features athlete, the result revealed that if a woman is trying to make it in sports through prize money, sponsorship and endorsement, tennis is the best sport to pick. This highlights a challenge for athletes in other sports as they aim to improve their commercial viability.

Likewise, there seems to be a limitation for athletes in team sports such as football, basketball and even athletes. The athletes on these lists are those involved in individual sports such as Tennis, Gold and Figure Skating. This lean towards individual sports in top-earning female athletes is not like that with the male athletes where those involved in team sports still have opportunities for brand endorsements. In the 2018 list of highest paid athletes; seven of the top ten plays in team sports like Basket Ball, Football and American Football. This further presents an additional challenge for sportswomen in team sports to become brand ambassadors.

The United States has the highest number of athletes over the years, an indication that the country of origin may also be a contributing factor in becoming a brand ambassador. Perhaps the population of the country, coupled with a national interest in the sports could have propelled the public perception of the athletes, and then brands find them appealing. This closely relates to the case of P.V. Sindhu, the Badminton player from India; her endorsement money was 16 times more than her prize money for the year. She succeeded on the court, the population of India found were appealing, and brands wanted to be associated with her. 
The impact of country of origin can also be further contextualised in terms of residence and wiliness to be associated with a different country. For example, Maria Sharapova has been living and training in the US for many years, but she represents Russia. Likewise, Annika Sörenstam is considered a Swedish American. This perhaps opens the idea of the possibilities of using the association with different countries to boost the marketability of athletes.

Brands want athletes that can appeal their target audience, with the possibilities of transferring an embedded meaning in their celebrity status to the products, irrespective of their sports or country of origin. It must be said that brand endorsement is a business decision made by brand managers; their decisions may therefore not be questioned. As celebrities are being courted by advertisers to endorse their products (Aririguzoh, et al., 2019), stakeholders within the sports sectors need to acknowledge their responsibilities to improve the commercial viability of sportswomen, especially cross team sports and developing countries.

Governing bodies and rightsholders, especially for team sports needs to consider ways of making their sports more appealing to the public, especially in the context sportswomen that often does not receive media coverage. If people do not see the sports in traditional media, another form of media can be used. Governing bodies can use other media to complement their publicity. This can have a cascading effect on the sports and the sportswoman. Individuals within the team sports can build on the publicity already available to enhance their commercial viability.

It is not easy to get to the top of the game and not to talk about the top of the endorsement pyramid, and the sportswoman as got a role to play in integrating their brand and positioning themselves for brand endorsements. Sportswomen must tell their story, appeal and engage with the diverse audience (Mogaji, et al., 2018). They can also use their own media channel for endorsement (Abeza, et al., 2017) Brand endorsements is getting more competitive as there are various options for brands to work with. Sportswomen are competing with sportsmen, musicians, artist and social media influencers to become brand ambassadors. Also, for those in team sports, they are competing with their teammates in becoming brand ambassadors. This suggests that sportswomen need to take responsibilities for their brand and importantly, working with the right team that can further develop their brand as they aim to beat the competition.

For those who manage the sportswomen brands, it is essential that they make more effort to integrate their clients' brand across different touchpoints better. Taking into consideration the public perception of sportswomen's brand, this could be challenging. Also, there could be an additional challenge in the Organisation because the managers have different sportswomen on 
their roster, however, if a sportswoman as commits her brand into their care, it deserves to be well managed. It would not be surprising if a sportswoman decided to leave a talent agency because she is not receiving the right support or feeling lost in the crowd of other athletes. While recognising these challenges with sportswomen, it will be a good idea to have a division that specifically works with sportswomen as a brand. This division, perhaps within the bigger talent agency can recognise the sportswomen's struggle, challenges and have the expertise to help them navigate through the endorsement maze.

Sportsmen have dominated the endorsement business, an indication of brand managers' interest in sportsmen's brand personality and congruency with the brands they endorse. No doubt this makes a commercial sense. However, Brands are missing out of the opportunities offered by sportswomen. However, brand managers should take more creative risks. Even if such risks do not make commercial sense, brand managers should see them as a part of their corporate social responsibility, particularly in the area of diversity and inclusion. Moreover, given that consumers have demonstrated a positive attitude towards brands that sponsor a less conventionally favourite sportsperson/team, there is an opportunity for more brands to sponsor sportswomen and their teams. Additionally, sportswomen offer brands an opportunity to reach new audiences, which, in turn, can lead to an increase in sales.

This present study extends the literature on sportswomen as brands, sports marketing and celebrity endorsements. They are revealing the prospects of non-team sports athletes achieving considerably more endorsement deals than team sports athlete. The contributing factor of the country of origin was also recognised, however this open opportunity for future research. Five research agendas are presented for future studies to extend knowledge and contribute to the literature on sportswomen sports marketing and celebrity endorsements.

Firstly, the personal brands of these highest paid sportswomen can be qualitatively explored. To have a deeper understanding of what made they different, unique and appealing to brands, unlike others. To explore how they have developed their brand, those who have contributed to their success and remaining commercially viable. Gaining access to these individuals for research may be a challenge, but it is worth considering. Analysis of media interview press release and different brand endorsement they have done could also be used to triangulate the study and offer a holistic understanding of their celebrity brand. This will also offer deeper insight for prospective sportswomen who want to go down the route of brand endorsement. 
Secondly, Research can also explore what makes non-team sports more commercially viable and appealing to brands than team sports, especially within the sportswomen context. Why are tennis players getting more endorsement than football players? Could it be about sports or media coverage? Understanding these unique differences can help governing bodies and talent managers improve their marketing and public relations strategies.

Thirdly, this present study can be replicated to understand the dynamics between the highranking male athletes. Top 10 male athletes can be identified form the Forbes list to highlight any significant tilt towards team sports or non-team sports or specific country of origin. This will extend knowledge about the differences and similarities between sportswoman and sportsmen's brand endorsement opportunities. Likewise, it will add to the literature on athlete brand, celebrity endorsement and sports marketing.

Fourthly, the impact of country of origin on brand endorsements in sports could also be empirically examined. Perhaps could the size of the United States be a contributing factor to having such number of citizens as top-earning sportswomen? Alternatively, better still do they have a better structure to work with sportswomen. For other countries, why are they not being well represented? Could it be about the facilities and opportunities available for sportswomen? These findings will be relevant for policymakers, governing bodies and government ministries responsible for sports development.

Lastly, the effort of Forbes in providing these lists is recognised and appreciated. However, it will be worthwhile to go beyond top 10 women athletes. Other sportswomen are doing well across different sports and other countries that could be mentioned if the list is extended. If this is something Forbes is not considering, future research can examine how other sportswomen are doing beyond the top ten. This extension will shed more light on the success stories and achievements of the sportswomen. Sportswomen will see it as a recognition of their achievement; Brands will be more likely to be interested in working with them. It will also encourage and motivate young people into pursuing sports, especially if they see someone from their sport and country.

\section{Conclusion}

For a sportswoman to become the highest paid female athletes in the world, she must be an American citizen who plays Tennis. This conclusion arrives form the content analysis of the top highest paid female athlete in the world for over ten years. Tennis players who are American citizens dominated the list. While this may be considered an achievement, it still concerns that it 
forms a small percentage of the endorsement market which has been dominated by sportsmen. Sportswomen still face challenges in becoming brand ambassadors

The sportswomen have decided to play a sport they like, even though brands and society may not find it attractive. With the understanding of challenges sportswomen face in becoming brand ambassadors, it is essential to recognise that some limitations are beyond the control of the sportswoman however they have a role to play in integrating their brands and in becoming the celebrity brand that can endorse a product - at least if not internationally, maybe nationally. The Governing bodies, Talent Managers and Brand Managers also have a crucial role in changing the narrative and constituents of this ranking.

Data was collected from information provided from Forbes, and it was limited to just ten female athletes over the years (excluding 2009 with 5). This could be considered a limitation for the study; however considerable effort has been put into the content analysis to ensure the validity and reliability of the findings. However, if the list has been extended to cover more sportswomen, the study might have arrived at a different conclusion. Theoretical and Managerial implications have also been highlighted, including research agendas and plans for future studies.

\section{References}

Abeza, G., O'Reilly, N., Séguin, B. \& Nzindukiyimana, O., 2017. The world's highestpaid athletes, product endorsement, and Twitter. Sport, Business and Management: An International Journal, 7(3), pp. 332-355.

Aririguzoh, S. A., Mogaji, E. \& Odiboh, O. O., 2019. The Effect of Celebrity Endorsements on Consumers' Buying Behavior in South West Nigeria. In: A. Gbadamosi, ed. Exploring the Dynamics of Consumerism in Developing Nations. Hershey, PA: IGI Global, pp. 176-194.

Badenhausen, K., 2018. The World's 100 Highest-Paid Athletes 2018: Behind The Numbers. [Online] Available at: https://www.forbes.com/sites/kurtbadenhausen/2018/06/05/the-worlds-100highest-paid-athletes-2018-behind-the-numbers/\#4c0621714dd0 [Accessed 1212 2018].

Berelson, B., 1952. Content analysis in communication research. Glencoe: Free Press.

Chan, K. \& Cheng, Y., 2012. Portrayal of females in magazine advertisements in Hong Kong. Journal of Asian Pacific Communication, Volume 22, p. 78-96.

Kolbe, R. H. \& Burnett, M. S., 1991. Content-analysis research: An examination of applications with directives for improving research reliability and objectivity. Journal of Consumer Research, Volume 18, p. 243-250. 
Krippendorff, K., 2013. Content analysis: An introduction to its methodology. Thousand Oaks: Sage.

Mogaji, E., 2015. Reflecting a diversified country: A content analysis of newspaper advertisements in Great Britain. Marketing Intelligence \& Planning, 33(6), pp. 908926.

Mogaji, E., 2016. Emotional Appeals in UK Banks' Print Advertisement. Luton, Bedfordshire: University of Bedfordshire, Unpublished PhD Thesis.

Mogaji, E., 2016. This advert makes me cry: Disclosure of emotional response to advertisement on Facebook. Cogent Business \& Management, 3(1), p. 1177906.

Mogaji, E., 2018. Emotional Appeals in Advertising Banking Services. London: Emerald.

Mogaji, E., Badejo, A. \& Charles, S., 2018. Sportswomen as Brand Ambsasdors: Prospects, challenges and possibilities, Greenwich, London: The Sportswomen project, University of Greenwich.

Mogaji, E., Czarnecka, B. \& Danbury, A., 2018. Emotional appeals in UK business-tobusiness financial services advertisements. International Journal of Bank Marketing, 36(1), pp. 208-227.

Mogaji, E., Farinloye, T. \& Aririguzoh, S., 2016. Factors shaping attitudes towards UK bank brands: An exploratory analysis of social media data. Cogent Business \& Management, 3(1), p. 1223389.

Neuendorf, K. A., 2002. The content analysis guidebook. Thousand Oaks, CA: Sage. Topend Sports, 2029. World's Highest Paid Women Athletes. [Online] Available at: https://www.topendsports.com/world/lists/earnings/women-paid.htm [Accessed 22 2019].

WTA, 2019. About WTA. [Online] Available at: https://www.wtatennis.com/about-wta [Accessed 22 2019]. 